\title{
Fatal complication of diffuse idiopathic skeletal hyperostosis (DISH): report of a case
}

\author{
Tahir Hussein Alsaadawi ${ }^{1}$
}

\author{
'Department of Rheumatology and Medical Rehabilitation, Imam-Alsadeq Teaching Hospital, Babylon-Hilla, Iraq. \\ Correspondence to Tahir Hussein Alsaadawi (email: tahiralsaadawi@yahoo.com ). \\ (Submitted: 12 June 2017 - Revised version received: 18 June 2017 - Accepted: 09 July 2017 - Published online: 26 September 2017)
}

\begin{abstract}
Diffuse idiopathic skeletal hyperostosis (DISH) is a non-inflammatory ossification involving at least four contagious vertebral bodies. It is mostly asymptomatic but the osteophytes can be rarely associated with severe complications. We report 65-year-old man who was admitted to the emergency department with severe shortness of breath and stridor not responding to medical treatment, which ended with tracheostomy lifesaving. Patient condition began 1 year ago as cervical spine pain with radiculopathy to the upper limbs, which increased to recurrent attacks of shortness of breath that responds to bronchodilators. During last months, this attack begins poorly and responds to medications and $\mathrm{O}_{2}$. Several radiological examination including $\mathrm{x}$-ray, $\mathrm{CT}$ scan, and MRI reveal bony mass in front of the cervical spine with hypertrophy of soft tissues bulging and compressed larynx. Invasive techniques such as laryngoscope done by otolaryngologist to take biopsy from soft tissue, which reveals normal examination. In one-day, severe attack was not responding to $\mathrm{O}_{2}$ and medications ended with tracheostomy to save life. It is advisable to take in consideration that patients with DISH mostly in cervical spines may be at risk of fatal complications including airway obstruction

Keywords DISH, shortness of breath, tracheostomy
\end{abstract}

\section{Introduction}

Diffuse idiopathic skeletal hyperostosis (DISH) is a tendency for ossification of ligaments, tendons and joint capsule insertions, most often affecting the spine. ${ }^{1}$ Calcification of the longitudinal ligaments (particularly anterior) can often produce the radiological appearance of 'wax dripping from a candle', distinct from the vertebral bodies.

The prevalence may be as high as $28 \%$. Elderly men are most commonly affected.

It is uncommon in patients younger than 50 years and rare in patients younger than 40 years. Although Forestier's disease is a symptomatic in general, previous research was reported dysphagia, dyspnea and dysphonia all together only in rare cases.

\section{Case Reports}

Patient's condition began 1 year ago as cervical spine pain with radiculopathy to upper limbs which developed to recurrent attacks of shortness of breath that responds to bronchodilators. During last months, these attacks begin poorly and respond to medications and $\mathrm{O}_{2}$. Several radiological examinations include $\mathrm{x}$-ray (Fig. 1), CT scan, and MRI (Fig. 2) reveal bony mass in front of the cervical spine with hypertrophy of soft tissues bulging and compressed larynx.

Invasive techniques as laryngoscope done by otolaryngologist to take biopsy from soft tissue reveals normal examination just inflammatory process and no malignant cells were seen. In one day, severe attack not responding to $\mathrm{O}_{2}$ and medications ended with tracheostomy to save life (Fig. 3).

\section{Discussion}

The suggested pathogenesis of DISH is the ossification and osteophytes formation which is the result of abnormal osteoblast cell growth and activity in bony ligamentous region. ${ }^{4}$

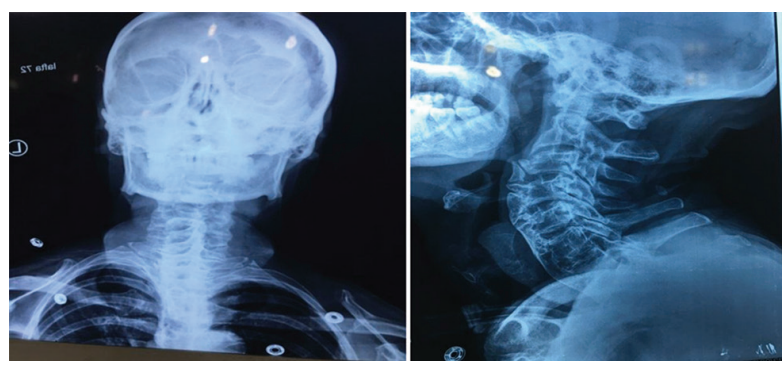

Fig. 1x-ray presentation of patient with DISH.
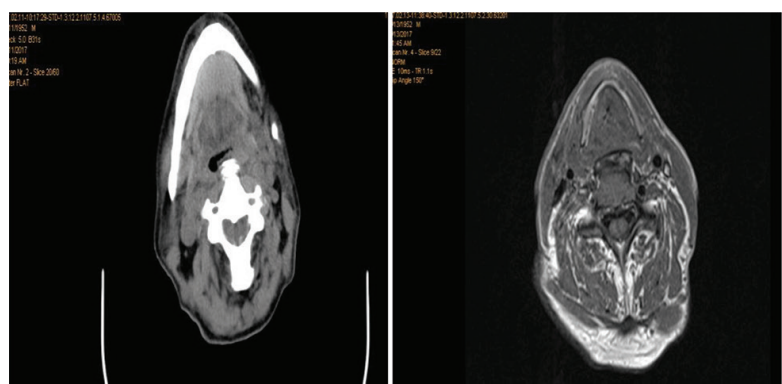

Fig. 2 CT scan of head and neck showing compressed larynx.
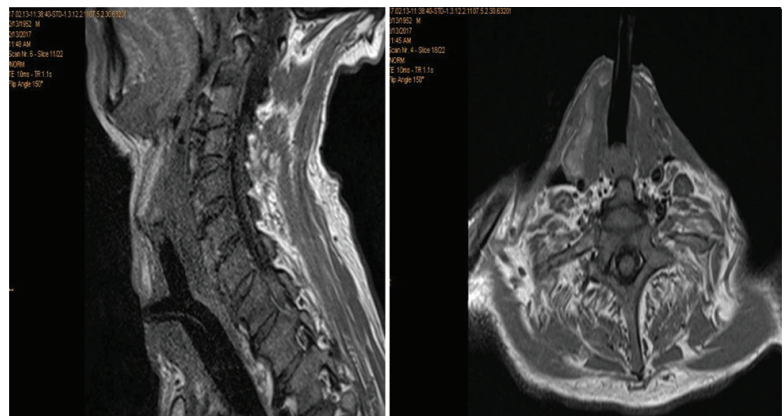

Fig. $3 \mathrm{MRI}$ of neck after tracheostomy. 

$11.2 \%{ }^{5}$

Airway symptoms prevalent in patients with DISH was

In our patient, ossifications and osteophytes were present at $c 3-c 7$ pronounced and bulged causing laryngeal manifestations, which might ended with severe airway obstruction. The possible mechanism is not only compression of the larynx but also paresis of terminal laryngeal nerve fibers, traumatic compromisation, and direct involvement of crico-artenoid joint.

Retro-cricoid inflammation can induce laryngeal edema, ${ }^{7}$ dysphonia, vocal cord immobility ${ }^{8,9}$ or stridor. ${ }^{10}$

Surgical treatment of DISH indicates that surgery is performed mainly via anterior approach (Smith-Robinson), ${ }^{11,12}$ however, we must be aware of the potentially severe complication of surgical treatment such as hematoma, Horner's syndrome, recurrent nerve palsy, superior laryngeal nerve palsy, and esophageal injury. ${ }^{13}$ Therefore, surgical treatment should be selected with care.

\section{Conclusion}

After appropriate history, clinical examination, diagnostic and radiological procedures, we diagnosed a DISH is a cause of symptoms in our patients.

In clinical practice, it is advisable to take in consideration fatal complications of DISH like airways obstruction.

\section{Conflict of Interest}

None.

\section{References}

1. Fábio A Nascimento, Luana Antunes Maranha Gatto, Roberto Oliver Lages, Heraldo Mello Neto, Zeferino Demartini, Junior, and Gelson Luis Koppe. Diffuse idiopathic skeletal hyperostosis: a review. Surg Neurol Int. 2014:5:S122-S125

2. Holton KF, Denard PJ, Yoo JU, Kado DM, Barrett-Connor E, Marshall LM. Osteoporotic fractures in men (MrOS) study group. Diffuse idiopathic skeletal hyperostosis and its relation to back pain among older men: the MrOS study. Semin Arthritis Rheum. 2011:41:131-138.

3. Ahn YJ, Hahn SH, Yang BK, et al. Diffuse idiopathic skeletal hyperostosis associated with dysphonia and dysphagia: a case report. J Korean Soc Spine Surg. 2006;13:327-331.

4. el Miedany YM, Wassif G, el Baddini M. Diffuse idiopathic skeletal hyperostosis (DISH): is it of vascular aetiology?. Clin Exp Rheumatol. 2000;18:193-200.

5. Jasmina S, Sandra Z, Suncica S, et al. Laryngeal manifestations of forestier's disease. J Med Sci. 2016:4:287-289.

6. Giger R, Dulguerov P, Payer M. Anterior cervical osteophytes causing dysphagia and dyspnea: an uncommon entity revisited. Dysphagia. 2006;21:259-263.

7. Marks E Schober, Swoboda H. Diffuse idiopathic skeletal hyperostosis causing obstructing laryngeal edema. Eur Arch Otorhinolaryngol. 1998;255:256-258.

8. Aydin K, Ulug T, Simsek T. Bilateral vocal cord paralysis caused by cervical spinal osteophytes. Br J Radiol. 2002;75:990-993.

9. Verstraete WL, De Cauwer HG, Verhulst D, Jacobs F. Vocal cord immobilisation in diffuse idiopathic skeletal hyperostosis (DISH). Acta Otorhinolaryngol Belg. 1998:52:79-84

10. Pfleger A, Eber E. Assessment and causes of stridor. Paediatr Respir Rev. 2016;18:64-72

11. Winslow CP, Winslow TJ, Wax MK. Dysphonia and dysphagia following the anterior approach to the cervical spine. Arch Otolaryngol. 2001;127:51-55

12. Saffouri MH, Ward PH. Surgical correction of dysphagia due to cervica osteophytes. Ann Otol Rhinol Laryngol. 1974;83:65-70.

13. Heeneman $\mathrm{H}$. Vocal cord paralysis following approaches to the anterior cervical spine. Laryngoscope. 1973;83:17-21.

This work is licensed under a Creative Commons Attribution-NonCommercial 3.0 Unported License which allows users to read, copy, distribute and make derivative works for non-commercial purposes from the material, as long as the author of the original work is cited properly. 